\title{
Origins and History of Sensors and Materials
}

\author{
Makoto Ishida \\ Toyohashi University of Technology \\ 1-1 Hibarigaoka, Tempaku, Toyohashi, Aichi 441-8580, Japan
}

The origins of Sensors and Materials go back to the early 1970s when the founding editor of the journal, Professor Kohji Toda, who was working at Stanford University as a visiting scientist, met then a graduate student, now Dr. Yuji Hazeyama, who was studying at Berkeley, at a small get-together near San Francisco, California. Professor Toda showed Dr. Hazeyama a few papers he had written. Dr. Hazeyama was stunned by the clarity and succinctness of his papers and wished all research papers published in scientific journals could be written in the same manner. They discussed the publication of science and predicted a sharp increase in scientific output from Asian countries in the future. Although there were many scientific journals based in America and Europe, not many English-language journals focusing on science, particularly non-society-affiliated journals, were based in Asia. After that, they met many times and discussed how to increase the visibility of scientific findings from Asia and agreed to work together in the future to promote publication of research in English by Asian scientists. Dr. Toda returned to Japan and resumed his work as a professor at the National Defense Academy and Dr. Hazeyama continued his doctoral work.

More than 10 years after their first meeting in California they met again in Tokyo and confirmed their enthusiasm for creating a scientific platform based in Asia. Fortunately, Professor Toda learned from his colleagues that the city of Toyohashi was planning to make the city the scientific center of the region and proposed a celebration of the 10th anniversary of the founding of Toyohashi University of Technology. Holding an international conference in Toyohashi was proposed for the occasion, and the local chamber of commerce and local industries provided support for the conference. They wanted to promote the city of Toyohashi and make it a capital of creativity and a center for generating creative information. Professor Toda decided to take advantage of the occasion as a stepping stone for the establishment of a new platform for the dissemination of scientific information in English. However, he did not want to hold just another international conference in the local city of Toyohashi but instead wanted to make the conference open to all researchers regardless of their academic affiliations; the conference was to be open to everyone who was interested in the promotion of science. The theme of the conference was ultrasonic technology; the history of the research was long but was moving rapidly in a new direction because surface acoustic wave (SAW) technology had advanced to the practical stage. The conference was expected to cover topics in many fields ranging from basic to applied acoustic electronics. An organizing committee was formed, centered around the work of Professor Tetsuro Tanaka and Professor Akira Kawabata of Kyoto University, Professor Toda's superiors when he was working for his doctoral degree.

*Corresponding author: e-mail: ishida@ee.tut.ac.jp

http://dx.doi.org/10.18494/SAM.2018.1800 
Subsequently, the proceedings of the conference were arranged and many papers were collected. The contents of the submitted papers were rigorously screened and the English carefully checked by native editorial experts. The practice of checking the English of submitted articles was not as common then as it is today. Although another conference on a similar topic was held in Japan in the same year, the Toyohashi International Conference on Ultrasonic Technology in 1987 was a success. The organizers of the conference wanted to hold a series of international conferences after this conference but decided that it would be more efficient to create a journal that covered the topics presented at Ultrasonic Technology 1987.

Editorial committee members were confident that they could launch and sustain such a journal and selected the area the new journal should cover. After lengthy discussions among Professor Toda and the editorial committee members of Ultrasonic Technology 1987, they selected Sensors and Materials as the journal title. A publishing office, MYU, was established by Dr. Hazeyama, and the plan to launch the first issue in 1988 was put into place. An editorial board including Japanese professors and researchers in the area of sensors was organized; however, it was not easy to include academics from overseas on the editorial board. Professor Henry P. Baltes, who had participated in the Transducers 1987 conference, submitted a paper to Sensors and Materials. The preliminary editorial committee explained the nature of the new journal to Professor Baltes, namely, that it was based in Japan, privately run, and open to all members of the scientific community. He liked the idea of a high-quality English journal; he particularly insisted that scientific information should come from multiple sources, and he agreed to serve as a board member of the newly created journal. In the early days of Sensors and Materials, Professor Baltes helped promote the journal a great deal and solicited papers from Europe. Nonetheless, it was not easy to collect high-quality papers consistently. The number of papers submitted to the journal was high in the first several volumes but dwindled thereafter, and the editorial board needed to modify their editorial stance by widening their scope and the acceptance standard for submitted articles. To revitalize the journal, they decided to ask a new editor to take over. After much discussion among editorial board members and associate editors, Professor Toda agreed to step down as the editor. In the middle of 1991 Professor Tetsuro Nakamura of Toyohashi University of Technology assumed the editorship and focused on the timely publication of issues of the journal. Unfortunately, Professor Nakamura suffered a stroke in the summer of 1994 and passed away. It was very sad that Professor Nakamura did not see the results of his efforts, as at that time the journal had just begun to gain momentum in the push for timely publication. Professor Susumu Sugiyama of Ritsumeikan University took over the editorship. After his retirement, the current editor-in-chief, Makoto Ishida (Professor of Toyohashi University of Technology), assumed the role of editor-in-chief.

It should be mentioned that throughout the history of Sensors and Materials, many distinguished researchers have helped promote this journal. In particular, Professor Kiyoshi Toko of Kyushu University, who is a leader in the field of biosensors, particularly in the field of taste and olfactory sensors, has helped in the publishing of this journal by providing advice regarding the editorial policy. We sincerely thank Professor Toko for his continuous contribution to the promotion of Sensors and Materials. More recently, Professor Jürgen Wilde has promoted the journal mainly in Europe, and Professor Shuvo Roy has taken over the role of 
editor in the United States. In addition, Professor Koji Mitsubayashi and Professor Kazusuke Maenaka continue to give us valuable editorial advice as associate editors.

We requested that Professor Toda write the history of Sensors and Materials; however, he became seriously ill, and sadly he passed away in May 2017 at the age of 76 . We sincerely thank him for his efforts in launching Sensors and Materials and hope he rests in peace. 